\title{
Improving Growth and Productivity of Early-season High-tunnel Tomatoes with Targeted Temperature Additions
}

\author{
Britney Hunter, Dan Drost ${ }^{1}$, and Brent Black \\ Department of Plants, Soils, and Climate, Utah State University, 4820 Old \\ Main Hill, Logan, UT 84322-4820
}

\author{
Ruby Ward \\ Department of Applied Economics, Utah State University, 3530 Old Main \\ Hill, Logan, UT 84322-3530
}

Additional index words. Solanum lycopersicum, protected cultivation, hoophouse, low tunnels, root zone heating

\begin{abstract}
In northern climates where the growing season is shortened by cool spring conditions, high tunnels make it possible to plant and produce tomatoes (Solanum lycopersicum L.) at least 1 month earlier than in the field. However, limited high-tunnel research has been performed in arid high-elevation regions that experience extreme diurnal temperature fluctuations. High tunnels are designed to be passively heated; therefore, additional protection from frost may be warranted if growers wish to plant significantly earlier than normal. Low tunnels built within a high tunnel reduce the energy requirement by concentrating heat around the plants, particularly when a heat source is placed inside the low tunnel. 'Sunbrite' tomatoes were transplanted through black plastic mulch in four high tunnels in North Logan, UT (lat. $41.73^{\circ} \mathrm{N}$, long. $111.83^{\circ}$ W, 1382 m elevation) on 17 Mar., 30 Mar., and 7 Apr. in 2009 and on 19 Mar., 30 Mar., and 9 Apr. in 2010. Low tunnels were constructed over each row, and three supplemental heat treatments (unheated, soil-warming cables, and soil-warming cables plus 40-W incandescent lights) were tested to improve plant performance. The highest total marketable yield was achieved for earliest planting dates in both 2009 and 2010. In 2009, earlyseason yield was significantly greater when both the soil + air were heated, but only for the earliest planting date. In 2010, soil heat alone and in conjunction with air heat significantly improved early-season yield. Information gathered in this study on planting dates, yield, and energy costs provides valuable production and economic information to growers in arid high-elevation climates who desire the benefits of growing early-season tomatoes in high tunnels.
\end{abstract}

High tunnel use throughout the United States is on the increase as a result of earlier crop production and the opportunity to exploit local markets with regionally grown produce (Carey et al., 2009; Knewtson et al., 2010). In regions with short growing seasons, extending the production period can have significant economic benefit (Rader and Karlsson, 2006; Rowley et al., 2010; Waterer, 2003). Tomatoes (Solanum lycopersicum L.) are the most commonly grown high-tunnel crop because

\footnotetext{
Received for publication 3 Jan. 2012. Accepted for publication 26 Mar. 2012.

Funding was provided by grants from the Western Sustainable Agriculture Research and Education (project \#SW07-035) program and the Utah Dept. of Agriculture and Food-Specialty Crop Block Grant program with additional funding from the Utah Agricultural Experiment Station-Utah State University (journal paper number 8386).

We gratefully acknowledge the technical assistance of James Frisby.

Use of trade names does not imply an endorsement of the products named or criticism of similar ones not named.

${ }^{1}$ To whom reprint requests should be addressed; e-maildan.drost@usu.edu.
}

overall eating quality when compared with field-grown fruit.

The benefits of high-tunnel production have been explored in other states including Missouri, Connecticut, and New Jersey (Chism, 2002; Gent, 1992; Reiss et al., 2004), but research in arid high-elevation regions is lacking. In arid high-elevation climates like Utah, daytime temperatures spring can be quite warm $\left(10\right.$ to $\left.20{ }^{\circ} \mathrm{C}\right)$ even when nighttime temperatures are below freezing (Moller and Gillies, 2008). These extreme diurnal temperature variations can limit the length of the growing season for outdoor-grown vegetables. However, warm temperatures during the day and sunny skies could be used advantageously when high tunnels are incorporated into a farm's production system. Utah gets more solar radiation on average than other parts of the United States that conduct hightunnel tomato research. On average, the western United States receives $18-21.6 \mathrm{MJ} \cdot \mathrm{m}^{-2} \cdot \mathrm{d}^{-1}$ of solar radiation in April and 21.6-25.2 $\mathrm{MJ} \cdot \mathrm{m}^{-2} \cdot \mathrm{d}^{-1}$ in May, whereas during the same period, regions of the central and eastern United States receive 14.4-18 and 18-21.6 $\mathrm{MJ} \cdot \mathrm{m}^{-2} \cdot \mathrm{d}^{-1}$, respectively (Wilcox and Marion, 1994). Increased solar radiation should result in more accumulated heat units in a high tunnel compared with climates with more cloudy conditions. Arid climates also have the advantage of low relative humidity that should limit the development of problematic diseases common to more humid regions (Lamont, 2005; Wells and Loy, 1993).

In most of the Great Basin region (USDA hardiness zones $5 \mathrm{a}$ to $6 \mathrm{~b}$ ), tomatoes are typically transplanted outdoors in mid- to late May and begin to ripen in early August, whereas high-tunnel tomatoes can be planted 5 to 7 weeks earlier. Choosing an appropriate planting date is an important decision for growers in these climates. A 2-week delay in planting was shown to delay ripening by 2 weeks for early high-tunnel tomatoes transplanted in Connecticut (Gent, 1992). However, early-season cold weather makes planting risky during late March and early April even when grown in high tunnels. Row covers and low tunnels have been shown to provide some frost protection for early field-planted tomatoes (Ankara, 2001; Emmert, 1956; Waggoner, 1958) and could be used in combination with high tunnels.

Typical outdoor early spring temperatures (March and April) in northern Utah range from 10 to $20{ }^{\circ} \mathrm{C}$ during the day and -5 to $5{ }^{\circ} \mathrm{C}$ at night (Moller and Gillies, 2008). Day temperatures inside a high tunnel normally reach 20 to $30{ }^{\circ} \mathrm{C}$, which is considered to be optimal for tomato (Kinet and Peet, 1997). However, nighttime temperatures in a high tunnel are typically only 1 to $4{ }^{\circ} \mathrm{C}$ warmer than the outside temperature, and consequently the high-tunnel environment is still susceptible to chilling or freezing conditions at night (Wien, 2009). Tomato plants are susceptible to chilling injury when exposed to temperatures below $10^{\circ} \mathrm{C}$ (Kinet and Peet, 1997) and grow best when temperatures are 25 to $30{ }^{\circ} \mathrm{C}$ during the day and 16 to $20^{\circ} \mathrm{C}$ 
at night (Csizinszky, 2005). Tomatoes are known to compensate growth when day or night temperatures are below optimum provided temperatures are optimal during the opposite period (Calvert, 1964).

The addition of rowcovers can increase temperatures 2 to $6{ }^{\circ} \mathrm{C}$, and polyethylene rowcovers alone were shown to protect tomato plants from freezing when outside temperatures were $-3.8{ }^{\circ} \mathrm{C}$ (Emmert, 1956; Waggoner, 1958). Low tunnels have also been shown to promote earlier tomato harvest and increase total yield within an unheated glasshouse, presumably by improving temperature conditions (Ankara, 2001). Waterer (2003) showed that heat unit accumulation, as measured by growing degree-days, was similar for low and high tunnels and both provided adequate plant protection when crops were planted in late May. However, this was after the risk of significant frost was passed. In New Jersey, polyester energy curtains placed inside a high tunnel were found to increase average night air temperatures $2.3{ }^{\circ} \mathrm{C}$ compared with the open field. In tunnels without curtains, temperatures were only $0.9{ }^{\circ} \mathrm{C}$ warmer than in the field (Both et al., 2007). In the arid, high-elevation regions of Utah, temperatures below $-7{ }^{\circ} \mathrm{C}$ often occur from mid-March to late April when growers would be transplanting tomatoes into high tunnels (Moller and Gillies, 2008). These low temperatures may seriously limit early hightunnel tomato production even when additional rowcovers are used. Therefore, targeted supplemental heat may aid in additional cold temperature protection during the early season.

Many high-tunnel production manuals advocate using protective structures like rowcovers and low tunnels inside high tunnels (Blomgren and Frisch, 2007; Byczynski, 2003; Lamont et al., 2005). However, few reports are available on the integration of supplemental heat additions and low tunnels within high tunnels. High tunnels typically do not use electricity; however, backup heating could provide the protection necessary to keep valuable plants alive in the early spring (Blomgren and Frisch, 2007). Supplemental heating is expensive, but costs may be reduced when used under low tunnels inside high tunnels, where heat would be concentrated around the plants. This approach has been used successfully for greenhouse tomatoes, where the amount of fuel needed to run the heating system was significantly reduced by targeting the heat at plant level using convection tubes (Hanna and Henderson, 2008). Soil warming has been shown to increase biomass accumulation and nutrient uptake for many crop greenhouse environments (Gosselin and Trudel, 1985; Hurewitz et al., 1984; Shedlosky and White, 1987). Although root zone heating can partly offset the adverse effect of low night air temperatures on greenhouse plants (Gosselin and Trudel, 1985; Janes and McAvoy, 1983), no published studies are known that assessed the effectiveness of root zone heating when high-tunnel air temperatures are near or below freezing.
The objectives of this project were to evaluate appropriate planting dates that provide early fruit production, to determine if low-cost supplemental heat sources can provide low-temperature protection for earlyplanted tomato, and to determine whether high-tunnel tomato production using these systems is economically viable.

\section{Materials and Methods}

Experiments were conducted in four identical high tunnels (replicates) on the Utah Agricultural Experiment Station Greenville Research Farm in North Logan, UT (lat. $41.77^{\circ} \mathrm{N}$, long. $111.81^{\circ} \mathrm{W}, 1382 \mathrm{~m}$ elevation, 135 freeze-free days) during the spring and summer of 2009 and 2010. The four tunnels were $12.8 \mathrm{~m}$ long and $4.3 \mathrm{~m}$ wide and were built with polyvinyl chloride hoops covered with a single layer of 6-mil greenhouse plastic (Black et al., 2008a). Two of the tunnels were managed organically and the others by conventional approaches, which were a continuation of a previous study and to facilitate future studies (Reeve and Drost, 2012). The organic tunnels were fertilized with composted chicken manure to provide 150 $\mathrm{kg}$ nitrogen $(\mathrm{N}) / \mathrm{ha}$. The compost contained $6.5 \mathrm{~g}$ of soluble $\mathrm{N}$ and $16.5 \mathrm{~g}$ of organic $\mathrm{N} / \mathrm{kg}$ of compost. The conventionally managed tunnels were fertilized as recommended from soil analysis and provided with 150 $\mathrm{kg} \mathrm{N} / \mathrm{ha} ; 50 \mathrm{~kg}$ phosphorus/ha, and $125 \mathrm{~kg}$ potassium/ha from various fertilizer sources. Compost and fertilizer were incorporated using a small tractor-mounted rototiller. During the growing season, an additional $50 \mathrm{~kg} \mathrm{~N} / \mathrm{ha}$ from fish emulsion or urea was injected with the irrigation water in the organic and conventionally managed tunnels, respectively. Prior research showed that there was no difference in tomato productivity between the organic and conventionally managed high tunnels (Reeve and Drost, 2012).

Supplemental heat. Each high tunnel had three 12-m long rows, which were divided into 4-m sections. Soil-warming cables were installed in six of the nine sections in each tunnel after the fertilizer application. Nonautomatic heavy duty soil-warming cables (Wrap-On Company Inc., Bedford Park, IL) were spaced $15 \mathrm{~cm}$ apart as directed by the product instructions and were buried $2.5 \mathrm{~cm}$ deep in the rows. The cables were attached to a Model 18500 heater control thermostat (Wrap-On Company Inc., Bedford Park, IL) with a remote soil sensor that was set to activate when soil temperatures dropped below $21^{\circ} \mathrm{C}$. Each soil warming cable used $700 \mathrm{~W}$ of electricity when activated. After the cables were installed, drip irrigation tape and black plastic mulch were laid in the tunnels to create three $90-\mathrm{cm}$ wide beds with $60-\mathrm{cm}$ walkways between the rows.

Three of the six soil-heated sections in each high tunnel were further modified to inexpensively warm the air around the planted tomatoes. Three rubber weatherproof pigtail sockets were spliced into heavy-duty extension cords and outfitted with $40-\mathrm{W}$ incandescent light bulbs. Lights were spaced $1.2 \mathrm{~m}$ apart and were located $60 \mathrm{~cm}$ above the soil surface. The lights were programmed to turn on when the air temperature dropped below $16^{\circ} \mathrm{C}$. Thus three heat treatments were created within each high tunnel: the unheated control, soil heat only, and the combination of soil + air heat. Individual electricity use monitors (Kill-A-Watt EZ meters; P3 International, New York, NY) recorded the amount of energy used by the cables and lights. The cost of electricity was calculated by multiplying kilowatts per hour (kWh) used by the current cost of electricity in Logan, UT ( $\$ 0.04622$ per $\mathrm{kWh}$ for general commercial service).

Low tunnels. To further increase frost protection and help retain heat around each respective plot, plastic rowcovers (low tunnels) were installed inside the high tunnels. Low tunnel supports were constructed from $1.3 \mathrm{~cm}$ diameter 3-m long conduit. The tubing was bent to make a $1 \mathrm{~m}$ tall by $1-\mathrm{m}$ wide square arch. The arches were secured over the rows by fitting them over $60-\mathrm{cm}$ long rebar, which was inserted in the soil $40 \mathrm{~cm}$. One arch was installed every $3.6 \mathrm{~m}$ to divide the plots. At the end of each plot, two arches were separated by $10 \mathrm{~cm}$ and the ends were covered with plastic to further separate the heat treatments. The low tunnels were covered with 2-mil constructiongrade plastic, and all plants inside a high tunnel were grown under the low tunnels.

The low tunnels were ventilated each morning (if needed) and covered again at the end of each day to avoid excessive heat buildup. Low tunnels were removed in midMay after the risk for frost. The high tunnels were ventilated as needed by opening the doors and lifting the side walls to regulate the temperatures between 20 and $30^{\circ} \mathrm{C}$. When the outdoor night temperature stayed above $12{ }^{\circ} \mathrm{C}$ (mid-June), the plastic on the high tunnels was removed and $40 \%$ shadecloth applied to minimize the potential for sunburn.

Watermark $^{\circledR}$ sensors (Irrometer Company, Riverside, CA) were used to monitor soil moisture and schedule irrigations. Sensors were placed at 15 - and $30-\mathrm{cm}$ soil depths and irrigation was applied when soil moisture readings approached $45 \mathrm{kPa}$ as recommended for a silt loam soil (Creswell et al., 2011). Plants were irrigated immediately after transplanting and approximately one time per week early in the season. As the plants grew and temperatures increased, water was applied three to four times per week at a rate of $\approx 25 \mathrm{~mm}$ per irrigation.

Transplant production. 'Sunbrite' (Seminis Seeds, St. Louis, MO) tomatoes were seeded into 50-cell flats and grown for 8 weeks in a heated greenhouse before transplanting into the high tunnels. Seeding occurred on 23 Jan., 5 Feb., and 18 Feb. 2009 and on 15 Jan., 27 Jan., and 9 Feb. 2010. Transplants were grown in soilless mix containing equal parts peatmoss, vermiculite, and perlite, and plants were fertilized to provide $100 \mathrm{mg} \mathrm{N} / \mathrm{kg}$ at 48-h intervals after emergence. The greenhouse was maintained at 
$21^{\circ} \mathrm{C}$ day and $18{ }^{\circ} \mathrm{C}$ night, and the daylength was extended to $16 \mathrm{~h}$ using sodium halide lights. Plants were brushed lightly by hand each day to strengthen the stems once the first true leaf emerged.

Planting dates and plant management. Tomatoes were transplanted in the high tunnels on 17 Mar., 30 Mar., and 7 Apr. 2009 and on 19 Mar., 30 Mar., and 9 Apr. 2010 and then covered with the low tunnels. The plants were spaced at $45 \mathrm{~cm}$ with eight plants per treatment. In 2009, all plants were pruned on 12 May by removing the three suckers closest to the ground. Suckers were bagged, weighed fresh, and then dried at $55^{\circ} \mathrm{C}$ for 1 week before determining dry weight. After suckering, plants were grown using a stake and weave system (Jett, 2004). Pruning weight data in 2009 did not equally represent differences between planting date and heat treatments because tomatoes from earlier plantings were larger; however, there was a difference in weight between heat treatments. In 2010, to more accurately measure the effect of planting date and heat treatment on pruning biomass, pruning took place exactly $38 \mathrm{~d}$ after transplanting for each planting date. No disease or insect problems were experienced during the course of this study.

In 2009 , tomatoes were harvested twice weekly beginning 7 July until 14 Aug. with early harvest considered to be 7 July through 24 July. In 2010, tomato harvest began on 14 July and ended on 26 Aug. with early harvest until 30 July (six harvests). Local field-grown tomatoes became available in mid- to late Aug. 2010. Tomatoes were harvested at the light red to red stage according to the U.S. standard for color classification (USDA-AMS, 1991) and separated into No. $1 \mathrm{~s}$ and No. 2s (locally marketable) and culls (disease, cracks, or deemed not marketable). Marketable tomatoes were sized into four categories: greater than $7.6 \mathrm{~cm}$ (large), 6.4 to $7.6 \mathrm{~cm}$ (medium), 5.1 to $6.4 \mathrm{~cm}$ (small), and less than $5.1 \mathrm{~cm}$ (culls). Marketable fruits were sold at the Logan Farmers' Market to assess market value.

Data collection and analysis. Soil and air temperature inside the high and low tunnels were determined with Type $\mathrm{T}$ thermocouples attached to a CR1000 data logger through an AM16/32 multiplexer (Campbell Scientific, Logan, UT) programmed to read soil and air temperatures every $30 \mathrm{~s}$. Air temperatures were measured at $30 \mathrm{~cm}$ above the soil surface, whereas soil temperatures were recorded $5 \mathrm{~cm}$ below the surface within each treatment plot. The high, low, and average temperatures were recorded hourly for the air and soil. Outside temperature and relative humidity data were collected with a sheltered HMP50 probe (Vaisala, Helsinki, Finland). Temperature data were used to calculate growing degree-hours based on the ASYMCUR heat unit model (Anderson et al., 1986) modified according to Black et al. (2008b). Temperature data were also used to calculate hours of chilling. One h of chilling was accumulated when the average hourly air temperature fell below $10{ }^{\circ} \mathrm{C}$.
A laboratory experiment was performed to gauge the warming capability of incandescent light bulbs within a low tunnel. A 3.6-m long low tunnel similar to those used in the high tunnels was constructed. A blackpainted copper plate, outfitted with five thermistor temperature probes connected to a CR10 data logger (Campbell Scientific), was placed in the low tunnel and positioned $\approx 30 \mathrm{~cm}$ from the center light bulb. A sheltered type-E thermocouple sensor was used to monitor air temperature. Lights were turned on for 30 min and then turned off for $30 \mathrm{~min}$ and the plate temperature recorded every $5 \mathrm{~s}$.

The labor required to set up tunnels, manage plant growth, and the time required for irrigation, ventilation, and harvest were recorded and materials and supply costs noted. Tomatoes were sold at the Logan Farmers' Market $(<\mathrm{http}: / /$ www.gardenersmarket.org $>)$ for $\$ 4.40$ to $\$ 5.50 / \mathrm{kg}$. These data were used to generate an enterprise budget, which was published elsewhere (Hunter et al., 2011). The experimental design was a randomized split plot design with planting date as the whole-plot factor and heat treatment as the sub-plot. Analysis of variance (SAS Institute, Cary, NC) was used to identify differences between planting dates and heat treatments and orthogonal contrasts used to separate specific planting date (early vs. others and mid vs. late) and heat (control vs. heat and soil heat vs. soil + air heat) effects. The least significant difference test $(\alpha=0.05)$ was used for multiple comparisons.

Partial budgeting was used to analyze the economic viability of soil heat and soil + air heat. Partial budgeting examines only what changes between new treatments (heat) over the base cost of high and low tunnels and thus assesses the potential profitability of the treatment. In this case the additional returns from increased yields from soil heat and soil + air heat combined are compared with the additional cost associated with the respective heat techniques. The result is the potential additional profit from the treatment.

\section{Results and Discussion}

Temperatures. Using low tunnels within high tunnels provided sufficient protection (across all planting dates and heat treatments) for $96 \%$ and $97 \%$ tomato plant survival in 2009 and 2010, respectively (data not shown). Temperatures inside and outside the tunnels in 2009 were as low as -3.5 and $-8{ }^{\circ} \mathrm{C}$, respectively. In 2009 and 2010, daily minimum temperatures inside the unheated low tunnels inside the high tunnel from 17 Mar. to 8 May were below $10{ }^{\circ} \mathrm{C}$ (Fig. 1A) with some overnight temperatures dropping below freezing. Although plant survival is important for early-season high-tunnel tomato production, temperatures should be warm enough during the day for growth to occur while avoiding
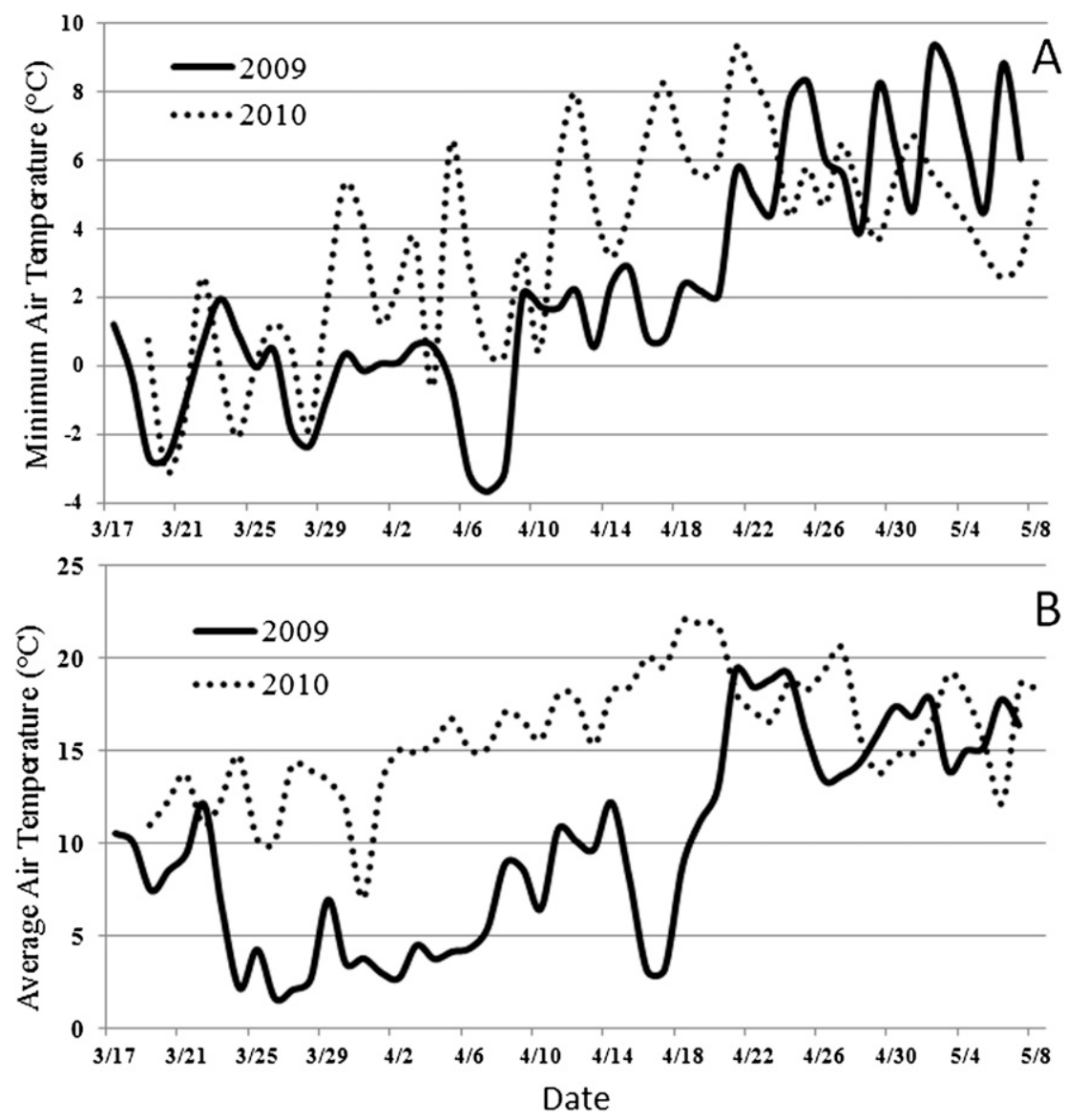

Fig. 1. Early-season minimum (A) and average (B) daily air temperatures inside an unheated (control) low tunnel within a high tunnel from late March to early May 2009 and 2010. 
superoptimal temperatures that adversely impact productivity (Peterson and Taber, 1991; Wolfe et al., 1989). Daily average temperatures inside the unheated low tunnels were sufficiently high during the early season for growth to occur (Fig. 1B). In general, average temperatures in an unheated low tunnel from late March to early May 2009 were cooler than in 2010.

The diurnal change in temperature outside the high tunnel and under the low tunnels inside the high tunnel on 2 clear days in late March is illustrated in Figure 2. Temperatures inside the high and low tunnels increased rapidly after sunrise and ventilation was required by $1000 \mathrm{~h}$ to maintain temperatures in the range of 30 to $35^{\circ} \mathrm{C}$. By $1600 \mathrm{~h}$, the temperature decreased so low tunnels were re-covered and high tunnel vents closed. On cloudy days, similar temperature patterns were noted under the low tunnels and inside the high tunnels, although the day-night temperature differences were not as extreme (data not shown). Without regular monitoring, low tunnel temperatures can quickly go from the optimal range for tomato to excessive, causing blossom loss or fruit abortion (Kinet and Peet, 1997; Peterson and Taber, 1991; Reiners and Nitzsche, 1993). Although flowering dates and blossom drop were not measured, tunnel temperatures were managed effectively (Fig. 2) and there were few episodes in which temperatures exceeded $35{ }^{\circ} \mathrm{C}$. In addition, cull fruit losses were generally not symptomatic of heat injury.

Although high tunnels alone provided $\approx 4{ }^{\circ} \mathrm{C}$ of cold protection, temperatures were regularly below freezing when planting early tomatoes in the Great Basin region of the western United States. Shen and Li (1983) noted that tomato can be cold-acclimated by exposure to short periods of chilling conditions and survive quite cold temperatures $\left(-3{ }^{\circ} \mathrm{C}\right)$. Temperature measurements in the low tunnels were comparable to earlier studies showing that low tunnels alone can protect tomato plants down to $-3.8^{\circ} \mathrm{C}$ (Emmert, 1956). On very cold nights (Fig. 1A), temperatures inside low tunnels were close to ambient air temperatures within the high tunnels. However, the addition of supplemental heat was enough to increase air temperature inside low tunnels by 2 to $3{ }^{\circ} \mathrm{C}$ when the soil + air were heated compared with unheated and soil heat alone (Fig. 2). Day temperatures were not different among the heat treatments.

The effect of diurnal temperature variations on productivity may be more complex than the effect of extreme temperatures in one direction. Gent and Ma (1998) reported that day/night differences in mean temperature (DIF) were greatest in March and April during vegetative, flowering, and early fruit growth periods. Our data support these findings and plants were regularly subjected to diurnal variations of more than $20{ }^{\circ} \mathrm{C}$. For greenhouse-grown tomatoes, larger DIF saves on heating costs (Gent et al., 1979) but may adversely impact earliness and productivity (Gosselin and Trudel, 1985). In this study, day temperatures would often increase by more than $25^{\circ} \mathrm{C}$ (Fig. 2) while average temperatures (Table 1) increased steadily as environmental conditions improved throughout April. Hurd and Graves (1985) also reported large diurnal temperature shifts and suggested that these diurnal cycles imparted increased cold temperature survival. Our plant survival data tend to support these conclusions.
Because the patterns of accumulated growing degree-hours (GDH) were similar in both years, only the results from 2009 are presented (Table 1). We did not analyze the differences between years because the seasonal temperature differences were expected (Fig. 1B). Each planting date was analyzed separately as a result of different time intervals between the planting dates and arbitrary measurement periods (every $\approx 15 \mathrm{~d}$ ). Planned comparisons indicated that more GDH accumulated when heat was added compared with the unheated controls for all planting dates. However, there were fewer differences in accumulated GDH between the soil heat and the soil + air heat treatment with later planting dates (Table 1).

The influence of the light bulbs on air temperature in this study may have been underestimated as a result of the location of the temperature sensors. The sensors likely could not pick up the heat radiating from the incandescent light bulbs as a result of interception by the sensor shield and the plant canopy. In the laboratory evaluation, a 40-W incandescent light inside a low tunnel caused the temperature of a flat black-painted copper plate to increase by $2{ }^{\circ} \mathrm{C}$ above ambient temperature in $\approx 15 \mathrm{~min}$. The temperature of the copper plate returned to the ambient temperature $\approx 20 \mathrm{~min}$ after the lights turned off. The infrared absorptivity of the flat black-painted copper plate $(0.97)$ is similar to the absorptivity of a green leaf $(0.96)$ because the albedo for each surface is similar. Therefore, incandescent lights may affect leaf temperature more than air temperature as a result of their location above the plants, and this should be investigated more carefully.

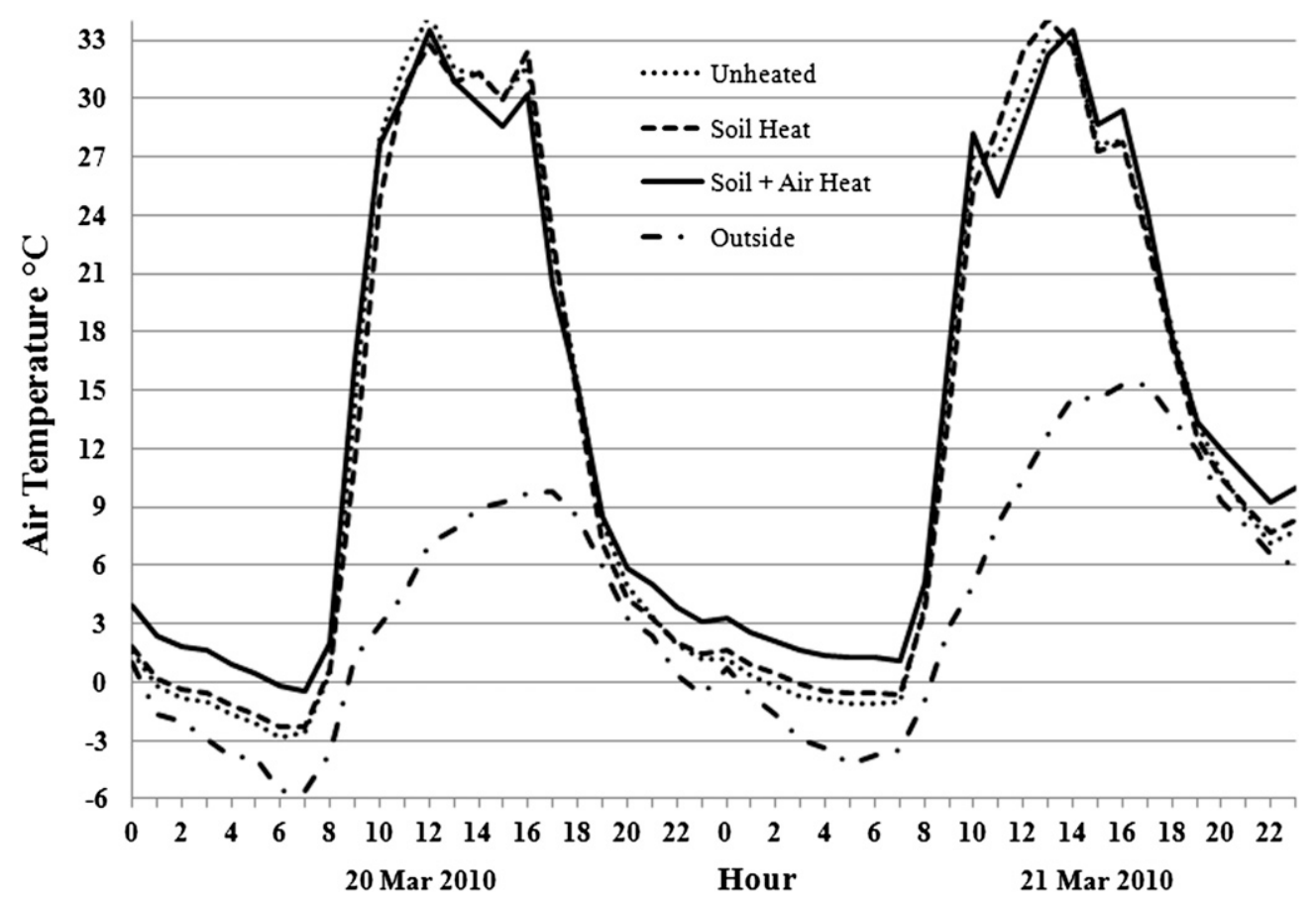

Fig. 2. The effect of targeted soil heat and soil + air heat on diurnal air temperature cycles within the tomato plant canopy under a low tunnel in a high tunnel in March when overnight air temperatures outside the high tunnel were below freezing. 
In 2009 , soil + air heat significantly reduced the accumulated hours of chilling (average hourly temperature less than $10{ }^{\circ} \mathrm{C}$ ) for tomatoes transplanted on 17 Mar. compared with heated soil only and the unheated control (Table 2). No significant differences in accumulated hours of chilling occurred between the heat treatments when planting on 30 Mar. or 7 Apr. 2009; however, plants with soil + air heat experienced $20 \%$ to $30 \%$ fewer hours of chilling. In 2010, accumulated hours of chilling were less than in 2009 (data not shown) although the general pattern was similar, because spring temperatures were generally warmer in 2010 than 2009 (Fig. 1A-B).

Plant growth. Early biomass accumulation was significantly greater with heat additions. Others have shown that low tunnels accelerate plant development, flowering, and improve early yields (Peterson and Taber, 1991; Reiners and Nitzsche, 1993). Plants with combined soil + air heat had greater pruning biomass compared with unheated or soil heat treatments for the first and last planting dates. Pruning biomass did not differ statistically among treatments when planted 30 Mar. 2009 as a result of increased plantto-plant variability (Table 3 ). In 2010, uniform sampling times ( $38 \mathrm{~d}$ after transplanting) provided more accurate comparisons of pruning biomass between planting dates and heat treatments. Although pruning biomass differed significantly among the three planting dates (Table 3 ), there was no significant interaction between planting date and heat treatments. Orthogonal contrasts indicate that plants receiving additional heat produced significantly more biomass than the unheated controls. However, there was no difference in pruning weight between the soil heat and the soil + air heat, suggesting that either heat treatment provided similar growth improvements.

Tomato yields. Early planting dates had a significant positive effect on early marketable yield. Fruit harvest began on 7 July for all planting dates in 2009 and on 14 July 2010 , $\approx 5-6$ weeks before local outdoor production. The early harvest achieved in our study (7 July 2009 and 14 July 2010) was comparable to the earliness achieved in previous studies in which tomatoes were grown in high tunnels under rowcover cloth instead of low tunnels (Reeve and Drost, 2012) and was similar to the earliness achieved with a high tunnel alone (Wells and Loy, 1993). However, tomatoes in our trial ripened more than 1 month earlier than those evaluated under low tunnels within an unheated glasshouse at a similar latitude (Ankara, 2001). Total marketable yield was significantly greater for the earliest plantings in $2009(P=0.022)$ and notably greater in $2010(P=0.104)$ compared with later planting dates. There was a trend for a decrease in total yield as planting dates were delayed (Table 4).

Early-season yield was significantly different among the three planting dates (Table 4) with those planted in mid-March producing significantly more yield in both years. Planting
Table 1 . The effect of targeted heat treatments on accumulated growing degree-hours (base $10{ }^{\circ} \mathrm{C}$ ) for three planting dates in 2009. ${ }^{2}$

\begin{tabular}{|c|c|c|c|c|c|}
\hline \multirow[b]{2}{*}{ Planting date } & & \multicolumn{4}{|c|}{ Accumulated growing degree-hours (base $10^{\circ} \mathrm{C}$ ) } \\
\hline & & 1 Apr. & 15 Apr. & 1 May & 15 May \\
\hline \multicolumn{6}{|l|}{17 Mar. } \\
\hline Unheated control & & 704 & 1404 & 2859 & 4702 \\
\hline Soil heat & & 769 & 1549 & 2961 & 4818 \\
\hline Soil + air heat & & 953 & 1989 & 3574 & 5475 \\
\hline \multicolumn{6}{|l|}{30 Mar. } \\
\hline Unheated control & & 82 & 745 & 2084 & 3930 \\
\hline Soil heat & & 107 & 915 & 2335 & 4129 \\
\hline Soil + air heat & & 97 & 958 & 2489 & 4320 \\
\hline \multicolumn{6}{|l|}{7 Apr. } \\
\hline Unheated control & & - & 557 & 2082 & 3844 \\
\hline Soil heat & & - & 547 & 2278 & 4499 \\
\hline Soil + air heat & & - & 666 & 2295 & 4180 \\
\hline Analysis of variance & $\mathrm{df}$ & \multicolumn{4}{|c|}{$P$ values } \\
\hline \multicolumn{6}{|l|}{17 Mar. } \\
\hline Heat treatments & 2 & 0.016 & 0.037 & 0.049 & 0.085 \\
\hline Unheated vs. heat & 1 & 0.021 & 0.047 & 0.083 & 0.127 \\
\hline Soil heat vs. soil + air & 1 & 0.019 & 0.042 & 0.041 & 0.070 \\
\hline \multicolumn{6}{|l|}{30 Mar. } \\
\hline Heat treatments & 2 & 0.232 & 0.117 & 0.109 & 0.440 \\
\hline Unheated vs. heat & 1 & 0.128 & 0.012 & 0.057 & 0.231 \\
\hline Soil heat vs. soil + air & 1 & 0.465 & 0.451 & 0.346 & 0.847 \\
\hline \multicolumn{6}{|l|}{7 Apr. } \\
\hline Heat treatments & 2 & - & 0.111 & 0.494 & 0.439 \\
\hline Unheated vs. heat & 1 & - & 0.285 & 0.264 & 0.281 \\
\hline Soil heat vs. soil + air & 1 & - & 0.063 & 0.930 & 0.525 \\
\hline
\end{tabular}

ㄹlanting dates were analyzed separately.

ANOVA $=$ analysis of variance.

Table 2. The effect of targeted heat treatments on accumulated hours of chilling for three planting dates in 2009. ${ }^{\mathrm{z}}$

\begin{tabular}{lrrrr}
\hline & \multicolumn{4}{c}{ Accumulated chilling degree-hours (base $\left.0^{\circ} \mathrm{C}\right)$} \\
\cline { 2 - 5 } Planting date & 1 Apr. & 15 Apr. & 1 May & 15 May \\
\hline 17 Mar. & 138 & 365 & 647 & 956 \\
$\quad$ Unheated control & 142 & 376 & 665 & 980 \\
Soil heat & 99 & 257 & 444 & 647 \\
Soil + air heat & & & & \\
& 21 & 138 & 290 & 370 \\
30 Mar. & 17 & 133 & 263 & 321 \\
$\quad$ Unheated control & 22 & 111 & 209 & 260 \\
Soil heat & & & & \\
Soil + air heat & - & 39 & 147 & 253 \\
& - & 36 & 122 & 176 \\
7 Apr. & - & 31 & 109 & 174 \\
$\quad$ Unheated control & & &
\end{tabular}

ANOVA

df

$P$ values

17 Mar.

$\begin{array}{llllll}\text { Heat treatments } & 2 & 0.005 & 0.004 & 0.003 & 0.003\end{array}$

Unheated vs. heat

10.030

Soil heat vs. soil + air

0.030

0.030

0.022

$\begin{array}{lll}0.003 & 0.002 & 0.002\end{array}$

30 Mar.

$\begin{array}{llllll}\text { Heat treatments } & 2 & 0.705 & 0.286 & 0.069 & 0.072\end{array}$

$\begin{array}{llllll}\text { Unheated vs. heat } & 1 & 0.744 & 0.301 & 0.065 & 0.051\end{array}$

$\begin{array}{llllll}\text { Soil heat vs. soil + air } & 1 & 0.481 & 0.223 & 0.093 & 0.141\end{array}$

7 Apr.

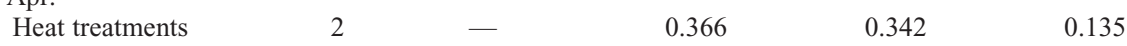

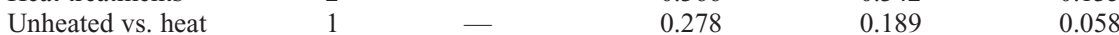

$\begin{array}{llllll}\text { Soil heat vs. soil + air } & 1 & - & 0.366 & 0.592 & 0.967\end{array}$

${ }^{\mathrm{z}}$ One chilling hour was accumulated when the average hourly temperature was between 0 and $10^{\circ} \mathrm{C}$. Planting dates were analyzed separately.

ANOVA $=$ analysis of variance. 
Table 3. The effect of targeted heat treatments on pruning biomass for three planting dates in 2009 and $2010 .^{\mathrm{z}}$

\begin{tabular}{|c|c|c|c|}
\hline \multirow{2}{*}{ Planting date } & & \multicolumn{2}{|c|}{ Dry wt (g) } \\
\hline & & 2009 & 2010 \\
\hline \multicolumn{4}{|l|}{ Early } \\
\hline \multicolumn{2}{|l|}{ Unheated control } & 57.7 & 16.4 \\
\hline \multicolumn{2}{|l|}{ Soil heat } & 56.2 & 27.3 \\
\hline \multicolumn{2}{|l|}{ Soil + air heat } & 118.2 & 39.9 \\
\hline \multicolumn{4}{|l|}{ Midseason } \\
\hline \multicolumn{2}{|l|}{ Unheated control } & 53.4 & 21.6 \\
\hline \multicolumn{2}{|l|}{ Soil heat } & 37.7 & 26.2 \\
\hline \multicolumn{2}{|l|}{ Soil + air heat } & 45.0 & 44.2 \\
\hline \multicolumn{4}{|l|}{ Late } \\
\hline \multicolumn{2}{|l|}{ Unheated control } & 7.4 & 32.5 \\
\hline \multicolumn{2}{|l|}{ Soil heat } & 6.2 & 69.9 \\
\hline \multicolumn{2}{|l|}{ Soil + air heat } & 14.1 & 61.5 \\
\hline ANOVA & $\mathrm{df}$ & \multicolumn{2}{|c|}{$P$ values } \\
\hline \multicolumn{4}{|l|}{ Early } \\
\hline Heat treatments & 2 & 0.003 & 0.084 \\
\hline Unheated vs. heat & 1 & 0.016 & 0.035 \\
\hline Soil heat vs. soil + air & 1 & $<0.001$ & 0.138 \\
\hline \multicolumn{4}{|l|}{ Midseason } \\
\hline Heat treatments & 2 & 0.422 & 0.125 \\
\hline Unheated vs. heat & 1 & 0.120 & 0.112 \\
\hline Soil heat vs. soil + air & 1 & 0.423 & 0.077 \\
\hline \multicolumn{4}{|l|}{ Late } \\
\hline Heat treatments & 2 & 0.258 & 0.052 \\
\hline Unheated vs. heat & 1 & 0.446 & 0.012 \\
\hline Soil heat vs. soil + air & 1 & 0.096 & 0.466 \\
\hline \multicolumn{4}{|c|}{$\begin{array}{l}\text { zAll plants were pruned on } 12 \text { May } 2009 \text { and thus } \\
\text { analyzed separately. In 2010, all plants were } \\
\text { pruned } 38 \text { d after planting. The interaction of } \\
\text { planting date and heat treatment in } 2010 \text { was not } \\
\text { significant. } \\
\text { ANOVA = analysis of variance. }\end{array}$} \\
\hline
\end{tabular}

before 20 Mar. increased early marketable yield by 0.3 to $0.4 \mathrm{~kg} /$ plant compared with late March plantings (Table 4) and by 0.60 to $1.32 \mathrm{~kg} /$ plant compared with those planted in early April. Tomatoes planted in late March had higher early marketable yields in $2009(P<0.001)$ and marginally greater yields in $2010(P=0.149)$ when compared with early April plantings. Therefore, delayed planting by 10-14 d would significantly reduce early-season yield even when environmental conditions (daylength and temperature) are generally improving during the same period. These results agree with the work of Gent (1992) in which a 2-week delay in planting date was shown to delay ripening by 2 weeks for early high-tunnel tomatoes. Gent (1992) found that planting in mid-April was best because earlier plantings suffered from nutrient deficiencies, presumably as a result of lowtemperature effects on nutrient uptake. No nutrient deficiencies were noted in our study.

Heat treatments significantly affected early marketable yield in both years. Early yields were significantly greater for the soil heat and soil + air heat treatments in 2009 and 2010 when compared with the unheated control (Table 4). Furthermore, in 2009 (a cool spring), soil + air heat improved early yield more than did soil heat alone $(P=0.006)$ but not in 2010 (warmer spring). There was a significant interaction $(P=0.012)$ between planting date and heat treatment on early marketable yield in 2009 in which adding heat significantly increased yield for tomatoes planted on 17 Mar. but did not alter yield for those planted on 30 Mar. or $7 \mathrm{Apr}$. planting dates (data not shown). In 2010, no interaction between heat treatments and

Table 4. The influence of planting dates and targeted heat treatments on early and total marketable tomato yields in 2009 and 2010.

\begin{tabular}{|c|c|c|c|c|c|}
\hline & & \multicolumn{4}{|c|}{ Marketable yield (kg/plant) } \\
\hline & & \multicolumn{2}{|c|}{2009} & \multicolumn{2}{|c|}{2010} \\
\hline & & Early $^{z}$ & Total $^{y}$ & Early & Total \\
\hline \multicolumn{6}{|l|}{ Planting dates } \\
\hline Early & & 2.04 & 5.14 & 1.21 & 4.55 \\
\hline Midseason & & 1.71 & 4.62 & 0.81 & 4.34 \\
\hline Late & & 0.72 & 4.15 & 0.61 & 4.08 \\
\hline \multicolumn{6}{|l|}{ Heat treatments } \\
\hline Unheated control & & 1.20 & 4.34 & 0.67 & 4.34 \\
\hline Soil heat & & 1.39 & 4.60 & 1.00 & 4.38 \\
\hline Soil + air heat & & 1.87 & 4.96 & 0.96 & 4.25 \\
\hline ANOVA & $\mathrm{df}$ & \multicolumn{4}{|c|}{$P$ values } \\
\hline Planting dates ${ }^{\mathrm{x}}$ & 2 & $<0.001$ & 0.035 & $<0.001$ & 0.167 \\
\hline Early vs. other & 1 & $<0.001$ & 0.022 & $<0.001$ & 0.104 \\
\hline Midseason vs. late & 1 & $<0.001$ & 0.196 & 0.149 & 0.292 \\
\hline Heat treatments & 2 & 0.001 & 0.235 & 0.043 & 0.853 \\
\hline Unheated vs. heat & 1 & 0.002 & 0.163 & 0.014 & 0.875 \\
\hline Soil heat vs. soil + air & 1 & 0.006 & 0.326 & 0.750 & 0.592 \\
\hline Planting $\times$ heat Interaction & 4 & 0.012 & 0.178 & 0.665 & 0.585 \\
\hline
\end{tabular}

${ }^{\mathrm{z}}$ Early marketable yield (first six harvests each year).

yTotal marketable yield includes the sum of No. 1 and No. 2 quality fruits (small, medium, large) only. xPlanting dates: early (17 Mar. 2009 or 19 Mar. 2010); midseason (30 Mar. 2009 and 2010); late (7 Apr. 2009 or 9 Apr. 2010).

ANOVA $=$ analysis of variance.

planting dates was observed. Although supplemental heat increased early marketable yield in both years, it had no significant effect on total marketable yield in either year (Table 4). However, under the cooler climate of 2009, there was a trend toward higher total yields when heat was added.

The influence of soil heat on tomato productivity is somewhat inconclusive. Trudel and Gosselin (1982) showed that warming the soil from 14 to $21{ }^{\circ} \mathrm{C}$ increased early yields by $47 \%$, whereas others (Gent and Melerba, 1994; Hurd and Graves, 1985) reported modest (10\% to $16 \%$ increase) or no effect on yield (Papadopoulos and Tiessen, 1983). In our study, we noted that soil heat increased early tomato yield by $32 \%$ (averaged over planting dates and years), whereas the combination of soil + air heat increased early yield by $46 \%$ over the unheated control. Most of the heating effects were associated with an increase in the number of large- and medium-sized fruits (data not shown). Largeand medium-sized fruits are the most desirable based on weight and marketability. Fruit numbers were greater, regardless of grade size, with earlier plantings compared with late plantings. Heat (soil or soil + air) positively affected fruit size and number distribution for early marketable yield and slightly $(P \leq 0.10)$ increased the number of fruits in the largest size class $(7.6 \mathrm{~cm}$ or greater $)$ in 2009 but not in 2010 (data not shown). The absence of supplemental heat did not significantly impact the number of early largeand medium-sized fruits in 2009 or 2010 and heating had no affect on No. 1 fruit quality.

Economics. Gent and Melerba (1994) noted that more energy is needed to heat the air compared with the soil in greenhouses. During periods of potential freezes, local tomato growers use propane to heat high tunnels. Although the potential exists for freezing temperatures to negatively impact earlyseason growth, increased profits from outof-season produce is appealing to growers looking to capture niche markets (Carey et al., 2009). Heating the soil + air costs $\$ 2.34$ per day per tunnel. Tomatoes planted in midMarch received additional heat for 8 weeks $(\operatorname{cost}=\$ 125 /$ tunnel $)$, which increased early yields and more than covered the extra heating costs in this study. For early planting dates, heat additions provided early production that more than covered the cost of heat in this study. For later plantings under more ideal conditions, additional heat resulted in a modest loss of revenue. This was the result of a similar supply and labor costs as with early plantings, marginal savings in electricity costs, and reduced revenues as prices decreased when field-produced tomatoes entered the marketplace.

Soil heat cables required on average 10.5 $\mathrm{kWh}$ of electricity at a cost of $\$ 1.11 / \mathrm{d}$ for a $29.3 \mathrm{~m}$ by $4.3-\mathrm{m}$ high tunnel, whereas adding lights required an extra $11.5 \mathrm{kWh}$ and $\$ 1.23 / \mathrm{d}$ for the same area. In both years, heat treatments were activated at planting and deactivated on 10 May when overnight low temperatures were consistently above 
Table 5. Partial budget comparing high tunnel tomato production with and without supplemental heat based on 2009 marketable yield data for the 17 Mar. planting date. ${ }^{z}$

\begin{tabular}{lrr}
\hline & Soil heat & Soil + air heat \\
\hline Added returns from heat ${ }^{\mathrm{y}}$ & $\$ 977.00$ & $\$ 1727.00$ \\
Cost of heat & & \\
$\quad$ Supplies & $\$ 184.02$ & $\$ 353.09$ \\
$\quad$ Labor $(\$ 10 / \mathrm{h})$ & $\$ 15.00$ & $\$ 30.00$ \\
Electricity $(\$ 0.04622 / \mathrm{kWh})(53 \mathrm{~d})$ & $\$ 58.83$ & $\$ 124.02$ \\
$\quad$ Total cost of heat & $\$ \frac{\$ 257.85}{\$ 507.11}$
\end{tabular}

Net profit (loss) to heat vs. no heat ${ }^{\mathrm{x}}$

$\$ 719.15$

$\$ 1219.89$

${ }^{2}$ Energy costs and returns will decrease slightly with later planting dates.

${ }^{\mathrm{y}}$ Returns for a $4.3 \times 29.3$ low-cost high tunnel containing 195 plants and tomatoes priced at $\$ 5.00 / \mathrm{kg}$. For full budget details, see Hunter et al. (2011).

${ }^{x}$ Returns for no heat source were $\$ 3998$. The returns listed are the income above the base value of no heat source. The additional yield is valued at $\$ 5.00 / \mathrm{kg}$. The breakeven yield is the additional cost of heat divided by the average price of $\$ 5.00 / \mathrm{kg}$.

$5{ }^{\circ} \mathrm{C}$ (Fig. 1). The added energy cost associated with heating the soil + air was $\approx \$ 2.34 / \mathrm{d}$ over $53 \mathrm{~d}$ for the earliest planting. Average daily energy costs decreased with later plantings because fewer cool nights occurred and the system did not operate as long or as often.

Early planting dates and supplemental heat had a significant positive effect on economic returns in both years. Out-of-season fruit can command a price premium double the regular in-season price (Koester, 2003). Local early tomato prices in Logan, UT, range from $\$ 4.40$ to $\$ 5.50 / \mathrm{kg}$ at a smaller farmers' market like Logan (data collected for this study) and up to $\$ 8.80$ to $\$ 11.00 / \mathrm{kg}$ at more lucrative markets in Salt Lake City or Park City. These prices are substantially higher than those reported by Waterer (2003). A detailed production budget generated from this project with input costs and revenues is available but did not include the heat components of this study (Hunter et al., 2011). The additional cost of targeted heating including supplies and installation labor would range from $\$ 2.05$ to $\$ 4.02 / \mathrm{m}^{2}$ depending on the heating system used (Table 5). Assuming a 3-year useful life on heat cables, the annual cost or depreciation expense associated with soil heat (average $53 \mathrm{~d}$ ) would be $\$ 184.02$ plus installation and electricity costs of $\$ 15.00$ and $\$ 58.83$ per year, respectively, for the midMarch planting date. To heat the air, supply costs were slightly cheaper, energy costs marginally more expensive, and additional installation costs were needed. Tomato yields (17 Mar. 2009 planting date) in the soil and soil + air heat treatments were $1.00 \mathrm{~kg} /$ plant and $1.77 \mathrm{~kg} /$ plant greater than the unheated controls. Assuming our plant spacing, a $29.5 \times$ 4.3-m high tunnel with soil heat or soil + air heat would produce an additional 195 and $345 \mathrm{~kg}$ of marketable tomatoes available for sale at an average seasonal price of $\$ 5.00 / \mathrm{kg}$. Heating the soil only would result in additional profit of $\$ 719.15$ compared with no supplemental heat, whereas soil + air heat would increase profits by $\$ 1219.89$ per tunnel (Table 5).

\section{Conclusion}

Growers wishing to maximize earlyseason tomato production in high tunnels should consider inexpensive ways to heat the soil and/or air. The results of this study showed significantly higher early-season growth and yields, resulting in positive economic returns. However, supplemental heating was not economically beneficial for later plantings and did not significantly increase total marketable tomato yield. Although more research is needed for detailed enterprise budgets that include heating options, it appears from our research that earlier production generated from modest targeted heat additions was more than sufficient to provide a good return on the investment.

\section{Literature Cited}

Anderson, J.L., E.A. Richardson, and C.D. Kesner. 1986. Validation of chill unit and flower bud phenology models for 'Montmorency' sour cherry. Acta Hort. 184:71-75.

Ankara, L.A. 2001. Effect of low-tunnel, mulch and pruning on the yield and earliness of tomato in an unheated glasshouse. J. Appl. Hort. 3:23-27.

Black, B., D. Drost, D. Rowley, and R. Heflebower. 2008a. Constructing a low-cost high tunnel. Utah State University Extension. 21 Dec. 2011. $<$ http://extension.usu.edu/files/publications/ publication/HG_High_Tunnels_2008-01photos. pdf $>$.

Black, B., J. Frisby, K. Lewers, F. Takeda, and C. Finn. 2008b. Heat unit model for predicting bloom dates in rubus. HortScience 43:20002004.

Blomgren, T. and T. Frisch. 2007. High tunnels: Using low-cost technology to increase yields, improve quality and extend the season. University of Vermont Center for Sustainable Agriculture, Burlington, VT. 21 Dec. 2011. $<\mathrm{http}$ ://www.uvm.edu/sustainableagriculture/ hightunnels.html $>$.

Both, A.J., E. Reiss, J.F. Sudal, K.E. Holmstrom, C.A. Wyenandt, W.L. Kline, and S.A. Garrison. 2007. Evaluation of a manual energy curtain for tomato production in high tunnels. HortTechnology 17:467-472.

Byczynski, L. (ed.). 2003. The hoop-house handbook. Growing For Market, Lawrence, KS.

Calvert, A. 1964. The effects of air temperature on conditions. J. Hort. Sci. 39:194-211.

Carey, E.E., L. Jett, W.J. Lamont, Jr., T.T. Nennich, M.D. Orzolek, and K.A. Williams. 2009. Horticultural crop production in high tunnels in the United States: A snapshot. HortTechnology 19: $37-43$. growth of young tomato plants in natural light
Chism, J. 2002. Warm-season vegetable production in high tunnels. The Kerr Center for Sustainable Agriculture. 21 Dec. 2011. <http://www. kerrcenter.com/publications/2002_proceedings/ warm-season_veggies.pdf>.

Creswell, T., G. Ruhl, J. Faghihi, S. Weller, B. Aly, and J. Masiunas. 2011. Midwest vegetable production guide for commercial growers. $21 \mathrm{Dec}$. 2011. <http://www.btny.purdue.edu/Pubs/ID/ ID-56>.

Csizinszky, A.A. 2005. Production in the open field, p. 237-252. In: Heuvelink, E. (ed.). Tomatoes. CABI Publishing, Oxfordshire, UK.

Dorais, M., A.P. Papadopoulos, and A. Gosselin. 2001. Greenhouse tomato fruit quality. HortScience 26:236-319.

Emmert, E.M. 1956. Plastic row covering for producing extra-early vegetables outdoors. Univ. of Kentucky Agr. Ext. Serv. Leaflet 167.

Gent, M.P.N. 1992. Yield response to planting date, ventilation and soil temperature on growth and nutrition of tomato high tunnels. Plant Soil 145:81-91.

Gent, M.P.N. and V. Melerba. 1994. Heating soil with hot air improves early yield and quality of greenhouse tomatoes. HortTechnology 4 : 277-281.

Gent, M.P.N. and Y.-Z. Ma. 1998. Diurnal temperature variation of the root and shoot affects yield of greenhouse tomato. HortScience 33:47-51.

Gent, M.P.N., J.H. Thorne, and D.E. Aylor. 1979. Split-night temperatures in a greenhouse: The effects on the physiology and growth of plants. Connecticut Agricultural Experiment Station Bulletin B781.

Gosselin, A. and M.J. Trudel. 1985. Influence of root-zone temperature on growth, development and yield of cucumber plants cv. Toska. Plant Soil 85:327-336.

Hanna, H.Y. and E.D. Henderson. 2008. Fuel type and releasing the heated air near plant roots reduced production cost of greenhouse tomatoes. HortTechnology 18:290-294.

Hunter, B., D. Drost, and R. Ward. 2011. High tunnel early tomato budget. Utah State Univ. Coop. Ext. 21 Dec. 2011. <http://extension. usu.edu/agribusiness/files/uploads/specialty/ pdf $/ 2011 \% 20$ Early $\% 20$ Tomato $\% 20 \mathrm{High} \% 20$ Tunnel\%20.pdf $>$.

Hurd, R.G. and C.J. Graves. 1985. Some effects of air and root temperatures on the yield and quality of glasshouse tomatoes. J. Hort. Sci. 60:359-371.

Hurewitz, J., M. Maletta, and H.W. Janes. 1984 The effects of root-zone heating at normal and cool air temperatures on growth and photosynthetic rates of tomatoes. Acta Hort. 148:871876.

Janes, H.W. and R. McAvoy. 1983. Deleterious effects of cool air temperature reversed by rootzone warming in poinsettia. HortScience 18: 363-364.

Jett, L.W. 2004. Production of tomatoes within a high tunnel. 21 Dec. 2011. <http://www.hightunnels. org/ForGrowers/WarmSeasonVegetables/ warmseasonvegtomprod.htm>.

Kinet, J.M. and M.M. Peet. 1997. Tomato. In: Wien, H.C. (ed.). The physiology of vegetable crops. CAB International, New York, NY.

Knewtson, S.J.B., E.E. Carey, and M.B. Kirkham. 2010. Management practices of growers using high tunnels in the central Great Plains of the United States. HortTechnology 20:639-645.

Koester, K. 2003. Greenhouse raspberry production guide. Dept. of Horticulture, Cornell University Publication 23. 21 Dec. 2011. <http://www. agrireseau.qc.ca/petitsfruits/Documents/ghrasp. pdf $>$. 
Krizek, D.T., R. Saftner, E. Park, J. Abbott, M. Camp, and D. Clark. 2006. Yield data from 2005 and instrumental and sensory evaluation of tomato fruits from plants grown in high tunnels at Beltsville, MD, or obtained from commercial sources. HortScience 41:1083.

Lamont, W.J. 2005. Plastics: Modifying the microclimate for the production of vegetable crops. HortTechnology 15:477-481.

Lamont, W.J., M.D. Orzolek, C. Rasmussen, and L. White. 2005. High tunnel production manual. 2nd Ed. Pennsylvania State University, Dept. of Hort. Ext Publ. High Tunnel Ser. 1, State College, PA.

Moller, A.L. and R.R. Gillies. 2008. Utah climate. 2nd Ed. Utah Climate Center, Logan, UT.

Papadopoulos, A.P. and H. Tiessen. 1983. Root and air temperature effects on the flowering and yield of tomato. J. Amer. Soc. Hort. Sci. 108: 805-809.

Peterson, R.H. and H.G. Taber. 1991. Tomato flowering and early yield response to heat buildup under rowcovers. J. Amer. Soc. Hort. Sci. 116: 206-209.

Rader, H.B. and M.G. Karlsson. 2006. Northern field production of leaf and romaine lettuce using a high tunnel. HortTechnology 16:649654.

Reeve, J. and D. Drost. 2012. Yields and soil quality under transition organic high tunnel tomatoes. HortScience 47:38-44.

Reiners, S. and P.J. Nitzsche. 1993. Rowcovers improve early season tomato production. HortTechnology 3:197-199.

Reiss, E., A.J. Both, S. Carrison, W. Kline, and J. Sudal. 2004. Season extension for tomato production using high tunnels. Acta Hort. 659:153-160.

Rowley, D., B.L. Black, D. Drost, and D. Feuz. 2010. Early-season extension using June-bearing 'Chandler' strawberry in high-elevation high tunnels. HortScience 45:1464-1469.

Shedlosky, M.E. and J.W. White. 1987. Growth of bedding plants in response to root-zone heating and night temperature regimes. J. Amer. Soc. Hort. Sci. 112:290-295.

Shen, Z.-Y. and P.H. Li. 1983. Induction of frost hardiness in tomato leaves by short-term cold acclimation. HortScience 18:730-732.

Trudel, M.J. and A. Gosselin. 1982. Influence of soil temperature in greenhouse tomato production. HortScience 17:928-929.
USDA-AMS. 1991. United States standards for grades of fresh tomatoes. 21 Dec. $2011<$ http:// www.ams.usda.gov/AMSv1.0/getfile?dDoc Name $=$ STELPRDC5050331 $>$.

Waggoner, P.E. 1958. Protecting plants from the cold. Connecticut Agr. Expt. Sta. Issue 614, New Haven, CT.

Ward, R., D. Drost, and A. Whyte. 2011. Assessing profitability of selected specialty crops grown in high tunnels. J. Agribusiness 29:41-58.

Waterer, D. 2003. Yields and economics of high tunnels for production of warm-season vegetable crops. HortTechnology 13:339-343.

Wells, O.S. and J.B. Loy. 1993. Rowcovers and high tunnels enhance crop production in the northeastern United States. HortTechnology 3:92-95.

Wien, H.C. 2009. Microenvironmental variations within the high tunnel. HortScience 44:235-238.

Wilcox, S. and W. Marion. 1994. U.S. solar radiation resource maps. National Renewable Energy Laboratory. 21 Dec. 2011. <http://rredc.nrel.gov/ solar/old_data/nsrdb/1961-1990/redbook/atlas/>.

Wolfe, D.W., L.D. Albright, and J. Wyland. 1989. Modeling row cover effects on microclimate and yield: I. Growth response of tomato and cucumber. J. Amer. Soc. Hort. Sci. 114:562-568. 